\title{
Propagación in vitro de Musa acuminata (Simmunds) plátano bocadillo del Chocó, Colombia, a partir del cultivo de meristemos apicales
}

\section{In vitro propagation Musa acuminata (Simmunds) plátano bocadillo of Chocó, Colombia, from apicals meristems culture}

\author{
Miguel A. Medina*, Cindy Lorena Medina*, Luz Karime Medina* \\ Resumen
}

\begin{abstract}
Objetivos: Propagar brotes adventicios a partir de meristemos apicales de plátano bocadillo o «primitivo» Musa acuminata, mediante cultivo in vitro. Metodología: Se propagaron in vitro brotes provenientes de ápices apicales extraídos de hijos de «plátano bocadillo» $M$. acuminata; los ápices se cultivaron en un medio de iniciación semisólido de Murashige y Skoog, que contenía $4 \mathrm{mg} / \mathrm{l}$ tiamina- $\mathrm{HCl}, 0,5 \mathrm{mg} /$ I de ANA, 0,5 mg/l de IBA y 0,5 mg/l de 6-BAP y pH ajustado a 5,8 y $1 \mathrm{~g} / \mathrm{l}$ de carbón activado y luego en un medio de multiplicación con cuatro tratamientos hormonales: (1) 0,3 mg/l de ácido naftalenoacético (ANA)+1 mg/l de bencilaminopurina (6-BAP), (2) 0,5 mg/l de ANA+1,5 mg/l de BAP, (3) $1 \mathrm{mg} / \mathrm{l} \mathrm{de}$ ANA+3 mg/l de 6-BAP, (4) $1 \mathrm{mg} / \mathrm{l}$ de ANA+3 mg/l de 6-BAP+2 mg/l de ácido giberélico (AG3). Resultados: A los 90 días, el número de brotes y tamaño de los brotes por explantes fue: $25,8 \pm 0,9$ brotes y longitud del brotes $8,5 \pm 0,2 \mathrm{~cm}$ y número de raíces $3,8 \pm 0,1$ y longitud de las raíces $2,1 \pm 0,4 \mathrm{~cm}$. La mejor combinación de los reguladores de crecimiento fue de $1 \mathrm{mg} / \mathrm{l}$ de ANA y $3 \mathrm{mg} / \mathrm{l}$ de 6-BAP, lo cual indica que es necesaria la presencia de la auxina y citoquinia para la brotación. El enraizamiento fue in vitro y a los 90 días las plantas tenían en promedio $5,8 \pm 0,4$ raíces y longitud de raíz $3,2 \pm 0,3 \mathrm{~cm}$. Los brotes se formaron y enraizaron directamente del explante. Las plantas enraizadas se transfirieron al campo de forma exitosa. Conclusiones: El plátano bocadillo se puede multiplicar de manera masiva, siendo la combinación de los reguladores de crecimiento, 6-bencilamino purina (6-BAP) y ácido naftalenacético (ANA) la que arrojó los mejores resultados con $1 \mathrm{mg} / \mathrm{l}$ de ANA y $3 \mathrm{mg} / \mathrm{l}$ de 6-BAP como las concentraciones más efectivas.
\end{abstract}

Palabras clave: Cultivo de tejidos, Meristemo apical, Musa acuminata, Plátano bocadillo.

\begin{abstract}
Objetives: To propagate in vitro adventitious shoots from apical meristems of «plátano bocadillo» o «primitivo» Musa acuminata. Methodology: It were propagated in vitro shoots tip from apical ápices extracted from children of plátano «bocadillo» $M$. acuminata, the apices were cultivated in a semisolid of Murashige and Skoog initiation medium containing $4 \mathrm{mg}$. l-1 thiamine $\mathrm{HCl}, 05 \mathrm{mg} / \mathrm{l} \mathrm{NAA}, 0.5 \mathrm{mg} / \mathrm{l} \mathrm{IBA}$ and $0.5 \mathrm{mg} / \mathrm{l} \mathrm{6-BAP}$ and $\mathrm{pH}$ adjusted to 5.8 and $1 \mathrm{~g} / \mathrm{l}$ activated charcoal, and then a multiplication medium with four hormone treatments: (1) $0.3 \mathrm{mg} / \mathrm{l}$ of naphthalene acetic acid (NAA) $+1 \mathrm{mg} / \mathrm{l}$ of benzylaminopurine (6-BAP), (2) $0.5 \mathrm{mg} / \mathrm{l} \mathrm{NAA+1.5} \mathrm{mg/l} \mathrm{BAP,} \mathrm{(3)} 1 \mathrm{mg} / \mathrm{l} \mathrm{NAA}+3 \mathrm{mg} / \mathrm{l} \mathrm{6-BAP,} \mathrm{(4)} 1 \mathrm{mg} / \mathrm{l}$ $\mathrm{NAA}+3 \mathrm{mg} / \mathrm{l} 6-\mathrm{BAP}+2 \mathrm{mg} / \mathrm{l}$ of gibberellic acid (GA3). Results: At 90 days, the number of shoots and shoots size by explants was: $25.8 \pm 09$ shoots and shoots length $8.5 \pm 0.2 \mathrm{~cm}$, and number of roots $3.8 \pm 01$, length of roots $2.1 \pm 0.4 \mathrm{~cm}$. The best combination of growth regulators was $1 \mathrm{mg} / \mathrm{l} \mathrm{NAA}$ and 3 $\mathrm{mg} / \mathrm{l}$ de 6-BAP indicating that the presence of auxin and cytokinin are necessary for sprouting. The rooting was in vitro, and at 90 days the plants had an average of $5.8 \pm 0.4$ roots and root length $3.2 \pm 0.3$ $\mathrm{cm}$. The adventitious shoots formed directly from the explants. Rooted plants successful were transferred to the field. Conclusions: «Plátano bocadillo» can multiply massively, being the combination of growth regulators: Naphtalene acetic acid NAA and Benzylaminopuriene 6-BAP with the best results using 1 $\mathrm{mg} / \mathrm{l}$ of NAA and $3 \mathrm{mg} / \mathrm{l}$ of 6 -BAP as more effective concentrations.
\end{abstract}

Keywords: Apical meristem, Musa acuminata, Plátano bocadilo, Tissue culture.

* Grupo de Investigación Biotecnología y Recursos Fitogenéticos, Laboratorio de Cultivo de Células y Tejidos Vegetales, Universidad Tecnológica del Chocó Diego Luis Córdoba, Quibdó, Chocó, Colombia- e-mail: mmedinarivas@gmail.com Fecha recepción: Julio 23, $2014 \quad$ Fecha aprobación: Noviembre 26, 2014 Editor asociado:Jiménez AM 


\section{Introducción}

Descripción taxonómica. Los bananos y plátanos son nativos del sudeste asiático y se derivan de dos especies silvestres, Musa acuminata Colla y $M$. balbisiana Colla (Simmunds y Sherphered 1955, Simmunds 1973). Las musáceas pertenecen a la clase de las monocotiledóneas, al orden Zingiberales y a la familia Musaceae, la cual incluye a los géneros Musa y Ensete. El género se divide en cuatro secciones: Autralimusa, Callimusa, Rhodochlamys y Emusa. Esta última sección comprende a las especies M. acuminata y M. balbisiana. El número básico cromosómico para la sección Eumusa es de n=11. Las musáceas comestibles usualmente se dividen en dos especies M. acuminata y M. balbisiana que son diploides (Simmonds 1962).

La poliploidía y el genomio de cada cultivar está representado con la letra A para indicar la procedencia de M. acuminata y con la letra B para M. balbisiana. De esta forma las letras A y B sirven para identificación de cultivares (Aguilar 1993).

El grupo AAA está constituido por varios tipos de bananos con alguna semejanza entre si (Soto 1992). La separación de estos, requiere de la aplicación de una clave de cinco puntos y quince descriptores morfológicos descrita por Simmonds (Soto 1992).

Las musáceas en todas sus variedades, constituyen el cultivo base para la alimentación calórica del departamento del Chocó; estos cultivos, a pesar de haberse adaptado a tierras bajas húmedas, son susceptibles a enfermedades como la sigatoka negra (Mycosphaerella fijiensis), herenque (Ralstonia solanancearum), mal de Panamá (Fusarium oxixporum) (Aular y Casares 2011) las cuales han puesto en riesgo el recurso genético para la alimentación y para establecer nuevos cultivos.

El plátano bocadillo, es un diploide AA (Angarita y Pérez 1984) resistente al gusano tornillo (Castniomera humboldtise), se usa como alimento desde hace cientos de años; es una fuente importante de calorías, de fácil adquisición por las comunidades por su amplia distribución en el departamento del Chocó y su bajo costo; se cultiva de forma natural sin necesidad de aplicar insumos agrícolas por lo que se ha convertido en un cultivo de pancoger. Este cultivo ha incrementado su valor social y económico, ha- ciendo necesario mejorar el rendimiento de producción y calidad del producto, mediante la introducción de tecnologías de reproducción eficientes que permitan aumentar la producción.

La mayoría de las especies comestibles del género Musa son partenocárpicas, no producen semillas y para su propagación se separan los hijuelos del cormo madre, por lo tanto, la tasa de propagación que se logra a partir de este método es muy baja además el riesgo de diseminación de plagas y enfermedades es mayor (Tezenas 1985, Sandoval et al. 1991).

Para mejorar la producción de plantas se hace uso de las características que tienen la células vegetales nucleadas de estar en capacidad de desarrollar un nuevo individuo sin que sea necesaria la fusión previa de gametos o totipotencia celular, permitiendo dar lugar a una respuesta morfogenética formando directamente órganos o embriones somáticos (organogénesis o embriogénesis directa) (Aguilar 1993, Aguilar et al. 2008).

Haciendo uso de la totipotencia celular se ha definido una alternativa biotecnológica, la técnica de cultivo in vitro de tejidos vegetales, que permite la propagación masiva de muchas especies vegetales, entre ellas plantas musáceas libres de enfermedades permitiendo que se realicen selecciones clonales de genotipos sobresalientes, sus características agronómicas, organolépticas y de adaptación a ambientes específicos, resistentes a estrés biótico y abiótico; además de que puede ocurrir durante todo el año por ser realizado en condiciones controladas de laboratorio (Angarita y Pérez 1984).

Las técnicas de cultivo de tejidos vegetales en musáceas mediante yemas apicales de hijuelos, constituyen una de las prácticas más importantes de la biotecnológica para la obtención de grandes volúmenes de plantas de plátanos y bananos libre de plagas y enfermedades fúngicas y bacterianas (Castro et al.2002) así como para la propagación clonal de plantas sanas, por su estabilidad genética y en la conservación e intercambio de germoplasma (Vuylsteke y De Langhe 1988, Grisales 1994, Hoyos et al. 2008, Ramírez et al. 2008).

Esta estrategia ha sido aplicada por varios investigadores en diferentes especies con buenos resultados para la propagación masiva de musáceas, Ortega et al. (2011) y Pérez et al. (2011) utilizando 
la técnica de inmersión temporal del cultivar de plátano vianda; Sandobal (1991) la utilizó en la propagación de plátanos y bananos; Ríos et al. (2013) para plátano «cambur manzano»; Uzcátegui (2009) en hartón doble tallo; Pérez et al. (2002) y Hoyos et al. (2008) en dominico hartón, en musa AAB cv henano; Ortega et al. (2011) en banano Williams; sin embargo, se dispone de poca información para la propagación in vitro del plátano primitivo «bocadillo». Por lo tanto, se pretendió desarrollar un método de micropropagación in vitro que permitirá la obtención masiva de clones de este género libres de patógenos para garantizar la permanencia del cultivo en el departamento del Chocó.

El método de micropropagación desde sus inicios ha tenido múltiples aplicaciones y diversas variaciones debido a que no es una metodología reproducible en todas las especies vegetales, porque la respuesta de una metodología depende de la configuración genética de la especie; por lo tanto, al no existir antecedentes en la propagación del plátano bocadillo del Chocó, se evaluaron diferentes concentraciones de auxina ANA y citoquinina 6-BAP en la respuesta cultural y morfogenética en cada experimento. Esta medotología se ha aplicado al cultivo de meristemos de diferentes especies y es de uso común en el laboratorio de biotecnología de la Universidad Tecnológica del Chocó, Quibdó, Colombia.

\section{Metodología}

Material vegetal. Se utilizaron los hijos de la planta de plátano bocadillo, que se trasladaron al laboratorio de biotecnología de la Universidad Tecnológica del Chocó. Inicialmente fueron reducidos de tamaño hasta $2,5 \mathrm{~cm}$ de diámetro y de 4 a $5 \mathrm{~cm}$ de altura, luego se lavaron con agua corriente y se desinfectaron con una solución de hipoclorito de sodio al 3\% durante 20 minutos. En cámara de flujo laminar se realizó una segunda reducción del ápice hasta llegar a un tamaño de 1,5 cm de diámetro de la base y de 2 a $3 \mathrm{~cm}$ de altura; el proceso de reducción de tamaño continuó hasta obtener el explante apropiado.

Fase de iniciación, establecimiento e inducción del crecimiento de explantes de plátano bocadillo. Durante esta fase se obtuvieron los brotes adecuados para la multiplicación in vitro de yemas apicales de plátano bocadillo. La extracción y siembra de los meristemos apicales se realizó en la cámara de flujo laminar después de haber sido desinfectados. Los meristemos aislados se cultivaron en un medio de cultivo semisólido de iniciación que contenía $4 \mathrm{mg} \cdot 1$ 1 tiamina- $\mathrm{HCl}, 0,5 \mathrm{mg} / \mathrm{l}$ de ANA, 0,5 mg/l de IBA, y $0,5 \mathrm{mg} / \mathrm{l}$ de 6-BAP y pH ajustado a 5,8, $1 \mathrm{~g} / \mathrm{l}$ de carbón activado, incubados inicialmente en la oscuridad por ocho días y luego por cuatro semanas en condiciones de fotoperíodo con luz blanca, hasta obtener brotes de $1 \mathrm{~cm}$ de longitud aproximadamente. Los medios de cultivo se esterilizaron en una autoclave bajo condiciones estándar de presión y temperatura $\left(1,1 \mathrm{~kg} \cdot \mathrm{cm}^{2}\right.$ y $\left.121^{\circ} \mathrm{C}\right)$ durante $20 \mathrm{~min}$.

Fase de multiplicación y alargamiento de los brotes. En esta fase se evaluó el tipo y la concentración de los reguladores del crecimiento a emplear en la multiplicación in vitro de plátano bocadillo. Para realizar este experimento se utilizaron vitroplantas provenientes de la etapa de iniciación en el medio de cultivo MS, empleado inicialmente, adicionándole cuatro combinaciones de reguladores de crecimiento; para ello se utilizaron como variables la relación auxina ANA, citoquinina 6-BAP y AG3 (Tabla 1). El pH de los medios de cultivos se ajustó a $5,7 \pm 0,1$ y se esterilizó a $121^{\circ} \mathrm{C}$ y a $1,1 \mathrm{~kg} / \mathrm{cm}^{2}$ de presión por $20 \mathrm{~min}$.

Se cultivó un explante por frascos de compota con $10 \mathrm{ml}$ del medio, los cuales se dejaron en una cámara de crecimiento a $27 \pm 1^{\circ} \mathrm{C}$ a 15 horas de fotoperíodo por 30 días; la intensidad luminosa fue 1.500 a 2.000 luz fría/suministrada por tubos fluorescentes de $36 \mathrm{~W}$, equivalente a $34-90 \mathrm{~m} \mathrm{E} / \mathrm{s} /$ $\mathrm{m}^{2}$. Para la propagación masiva, esta fase se repite varias veces hasta obtener el número de plantas deseadas.

El diseño experimental empleado fue completamente al azar, con 10 repeticiones por tratamiento y

Tabla 1. Concentración de citoquinina y auxina en medios de cultivos utilizados para la multiplicación in vitro de los brotes obtenidos en la fase de iniciación.

\begin{tabular}{cccc}
\hline Tratamiento & $\begin{array}{c}\text { Citoquinina } \\
\text { 6-BAP mg/l }\end{array}$ & $\begin{array}{c}\text { Auxina ANA } \\
\mathbf{m g} / \mathbf{l}\end{array}$ & $\begin{array}{c}\text { AG3 } \\
\mathbf{~ m g / l}\end{array}$ \\
\hline & 1,0 & 0,3 & 0,0 \\
2 & 1,5 & 0,5 & 0,0 \\
3 & 3,0 & 1,0 & 0,0 \\
4 & 3,0 & 1,0 & 2,0 \\
\hline
\end{tabular}


un frasco como unidad experimental. Las variables evaluadas fueron número y tamaño de brotes formados por explante y número y longitud de las raíces en los diferentes medios de cultivo.

Para evaluar los resultados obtenidos, los datos se procesaron estadísticamente mediante un analísis de varianza en el programa Cohort 2, versión 6,003. Para la separación de medias se utilizó la prueba de rangos múltiples de Duncan a un nivel de significación del $1 \%$.

\section{Resultados y discusión}

Actualmente se han desarrollado con gran éxito diferentes técnicas y metodologías para la micropropagación in vitro de musáceas, que permitan la obtención masiva de plántulas útiles en el establecimiento de cultivos comerciales; por ejemplo Pérez et al. (2013) reportan condiciones óptimas para la propagación del cultivar de plátano vianda «INIVITPV-2011» (AAB), aplicando el método de inmersión temporal, usando medio líquido MS suplementado con 2 mg.L-1 de 6-BAP; 3,5 mg.L-1de AIA; Ríos et al. (2013) propagaron plátano «cambumber manzano» usando medio de cultivo MS, con varias concentraciones de BA $(0,2,5$ y $5 \mathrm{mg} / \mathrm{l}$ con yemas apicales; en contraste, los datos que aquí se presentan son los primeros generados para el cultivar de plátano bocadillo.

Iniciación. El protocolo aplicado con el propósito de establecer un procedimiento in vitro de propagación masiva de plátano bocadillo, a partir del cultivo de meristemos apicales, arrojó que en la etapa de establecimiento, después de cuatro semanas de haber establecido el cultivo en condiciones de oscuridad se obtuvo un alto porcentaje de explantes viables y un bajo porcentaje de explantes contaminados u oxidados; hacia las cuatro semanas de cultivo, hubo brote de una yema apical, con una longitud de 4 a $5 \mathrm{~mm}$ aproximadamente; después de cuatro semanas adicionales en el mismo medio, hubo alargamiento de las hojas y alargamiento del vástago (1 a $3 \mathrm{~cm}$ ) y el alargamiento se incrementó con el tiempo sin que se observara brotación lateral (Figura 1A).

Durante esta fase, también se observó un ligero ennegrecimiento u oxidación en la base de los explantes, este fenómeno se incrementó con el paso del tiempo; sin embargo, las yemas fueron viables durante la fase. La oxidación puede estar asociada con compuestos fenólicos, responsables del ennegrecimiento, causado por enzimas oxidoreductasas que se liberan durante el proceso de obtención de los explantes por corte del tejido (Ramírez 1998). Este fenómeno es muy común en el laboratorio y lo hemos minimizado agregando carbón activado al medio de cultivo porque estas enzimas contenidas en el citoplasma y las vacuolas, catalizan reacciones en presencia de luz que pueden afectar la viabilidad y desarrollo de los explantes (Ramírez et al. 1998). La adición de $1 \mathrm{~g}$ por litro de carbón activado e incubado en la oscuridad durante dos semanas minimiza este fenómeno en cultivos de meristemos apicales según Sepúlveda et al. (2008)

Multiplicación de los brotes. A las ocho semanas (Figura 1B) se observó un alto número de explantes viables y explantes con yemas brotadas que provenían de yemas apicales de vástagos cultivados en medio con 6-BAP; en los medios de multiplicación también se observó la presencia de tres brotes de $3 \mathrm{~mm}$ (Figura 1C). Esta baja proliferación es muy común en clones de Musa con genoma balbisiana durante la primera fase de multiplicación (Colmenares y Gómez 2003), por lo tanto, las respuesta a proliferación en medios con 6-BA está relacionada al cultivar y al clon (Ramírez et al.2008). A las 12 semanas (Figura 1D), el incremento del número de brotes fue notablemente importante.

En la Tabla 2 se evidencia el incremento del número de brotes después de ocho semanas dependiendo del medio de cultivo; los brotes se trasplantaron cada dos semanas a un medio fresco con las mismas condiciones. Después de 16 semanas (Figura1E), el número de brotes en los medios tres y cuatro fue aproximadamente de 60 y se formaron plantas enteras. En esta fase no se observó ennegrecimiento ni contaminación.

Con el propósito de realizar comparaciones en el crecimiento de los clústeres mencionados antes, se separaron brotes individuales y se plantaron en un medio fresco que solo contenía como regulador del crecimiento AG3; la elongación de estos brotes fue similar, 3 a $4 \mathrm{~cm}$ después de ocho semanas, en ambos medios con y sin reguladores de crecimiento AG3; esto se pudo deber a que la concentración utilizada no fue la ideal o que predominó el efecto del ANA y 6-BAP sobre el AG3. El número de brotes 
Tabla 2. Efectos de tres concentraciones de 6-BAP, ANA y AG3 en el número de brotes, longitud del brote, número de raíces en la etapa de multiplicación después de ocho semanas de cultivo in vitro.

\begin{tabular}{lcccccc}
\hline $\begin{array}{c}\mathbf{N}^{\circ} \text { de brotes } \\
\text { por explantes }\end{array}$ & $\begin{array}{c}\text { Longitud de los } \\
\text { brotes } \mathbf{~ m ~}\end{array}$ & $\mathbf{N}^{\circ}$ de raíces & $\begin{array}{c}\text { Longitud de } \\
\text { las raíces } \mathbf{~ m ~}\end{array}$ & \multicolumn{2}{c}{$\begin{array}{c}\text { Concentración de reguladores } \\
\text { del crecimiento en mg/l } \\
\text { A-BAP }\end{array}$} & $\begin{array}{c}\text { ANA } \\
\text { AG3 }\end{array}$ \\
\hline $5,7 \pm 0,6$ & $10,4 \pm 0,3$ & $3,2 \pm 0,3$ & $2,3 \pm 0,8$ & 1,0 & 0,3 & 0,0 \\
$12,9 \pm 0,7$ & $9,8 \pm 0,1$ & $3,1 \pm 0,2$ & $2,7 \pm 0,5$ & 1,5 & 0,5 & 0,0 \\
$25,8 \pm 0,9$ & $8,5 \pm 0,2$ & $3,8 \pm 0,1$ & $2,1 \pm 0,4$ & 3,0 & 1,0 & 0,0 \\
$23,5 \pm 0,3$ & $8,5 \pm 0,5$ & $3,7 \pm 0,5$ & $2,3 \pm 0,5$ & 3,0 & 1,0 & 2,0 \\
\hline
\end{tabular}

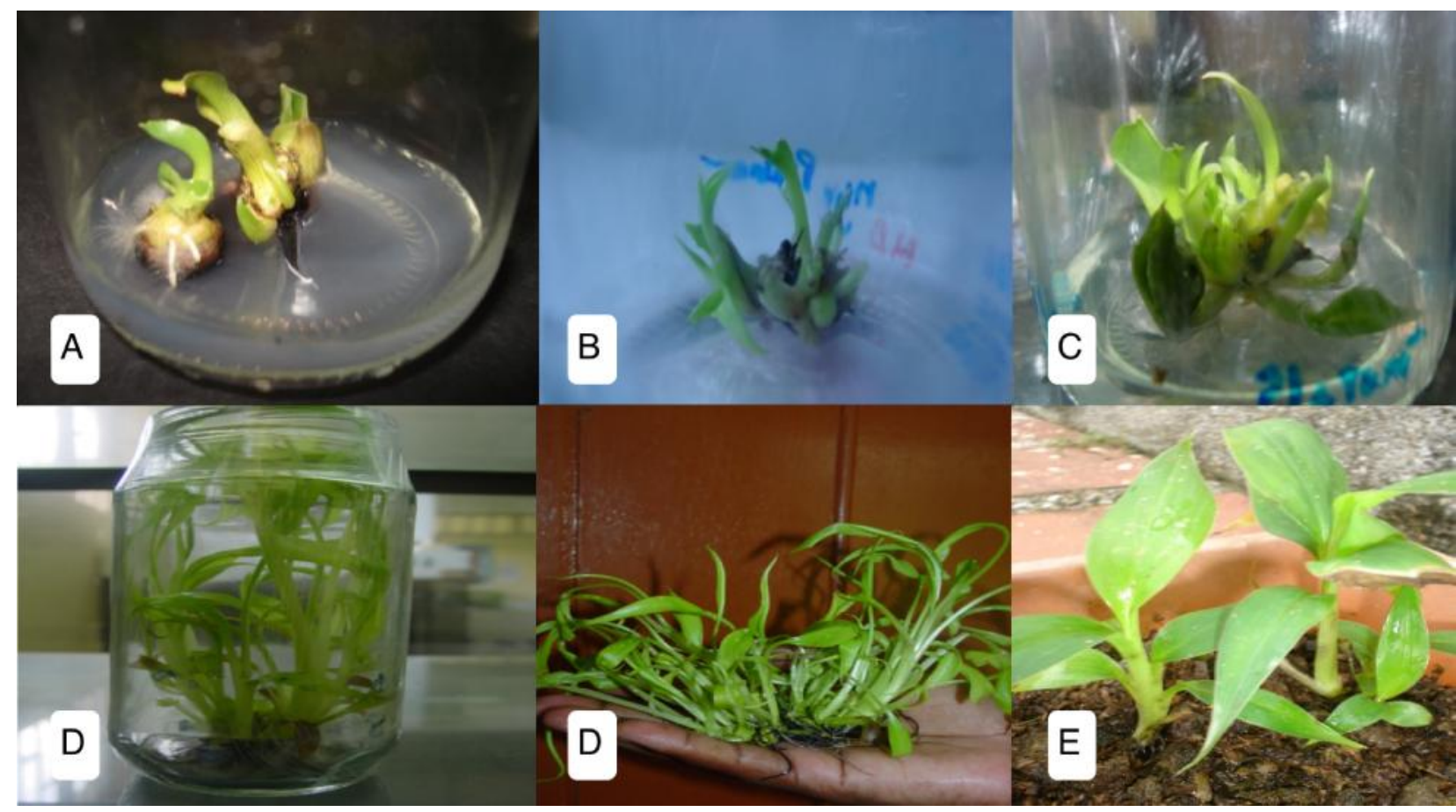

Figura 1. Proceso de propagación in vitro del plátano bocadillo Musa acuminata: Fase de iniciación. A. Cuatro semanas, fase de multiplicación; B. Seis semanas. C. Ocho semanas. D. Doce semanas. E. Transferencia a invernadero.

obtenidos en la fase de multiplicación fue mayor que los reportados por Silva et al. (2009) quienes obtuvieron 0,85 brotes por explantes al utilizar $5 \mathrm{mg} / \mathrm{l} \mathrm{de}$ BA y 2,3 brotes por explantes con concentraciones altas de BAP $10 \mathrm{mg} / \mathrm{l}$ en plátano «cambur manzano» clon (AAB) (Colmenares y Giménez 2003, Silva et al.2010) en plátano hartón y (Hoyos et al.2008); en hartón se observó la proliferación de brotes relativamente alta utilizando BAP.

Finalmente, Sandoval y Muller (1985) sostienen que los cultivos se pueden mantener indefinidamente transfiriéndose a un medio fresco cada 15 días; los brotes externos enraizados se preparan para su aclimatación y traspaso al campo y los internos pue- den continuar con el proceso de proliferación hasta obtener nuevos brotes. Esta situación se evidenció claramente en este trabajo y de un solo meristemo viable se obtuvieron en 90 días, más de 150 plántulas para ser aclimatadas y transferidas al campo. Durante este proceso es necesario eliminar tejidos necróticos externos, hojas y raíces marchitas, porque esto impide la proliferación de nuevos brotes.

\section{Conclusiones}

El plátano bocadillo se puede multiplicar de manera masiva lo cual es de gran utilidad para la erradicación de agentes patógenos y permite no sólo 
el intercambio de germoplasma sano sino también la multiplicación comercial, siendo la combinación de los reguladores de crecimiento, 6-bencilamino purina (6-BAP) y ácido naftalenacético (ANA) la que arrojó los mejores resultados con $1 \mathrm{mg} / \mathrm{l}$ de ANA y $3 \mathrm{mg} /$ 1 de 6-BAP como las concentraciones más efectivas.

Los clúster de brotes formados durante el proceso de multiplicación son la base para la propagación masiva de esta especie por esta vía, porque a partir de ellos se obtienen el número de plantas deseado por multiplicaciones sucesivas de los brotes asilados.

El uso del ácido goberélico AG3, en el medio de cultivo como fitohormona que permite el crecimiento rápido de los brotes, no presentó efecto importante en el crecimiento de las plantas in vitro, porque no hubo diferencia entre las plantas cultivadas en ausencia de esta fitohormona. El enraizamiento ocurrió in vitro en el mismo medio de proliferación obteniéndose raíces vigorosas que permiten su trasplante al suelo.

La oxidación de los explantes y la contaminación en la fase de establecimiento del cultivo son las principales causas de pérdida de material vegetal que se puede controlar con una buena desinfección y reduciendo la oxidación con carbón activado.

La multiplicación in vitro acompañada de una buena selección en el campo del material parental, permite disponer de plantas con excelentes condiciones agronómicas y fitosanitaria para conservar la especie y disponer de germoplasma.

\section{Literatura citada}

Aguilar M.1993. Micropropagacion in vitro de plátano (Musa $A A B)$ y costo del establecimiento en el laboratorio de la sede regional de San Carlos, ITCR. Tesis Bach. Ing. Agrónomo. Santa Clara: ITCR; 40 p.

Aguilar ME, Ortiz JL, Sandoval J. 2008. Embriogénesis somática en plátano y banano: perspectivas y limitaciones. Boletín Técnico/CATIE, $\mathrm{N}^{\circ} 27$. Turrialba: CATIE; $50 \mathrm{p}$.

Angarita A, Pérez M. 1984. Avances del proyecto Estudios orientados al control de la Sigatoka negra en plátano y banano. Segundo informe Colciencias (RF1000-4-36-83). $60 \mathrm{p}$.

Aular J, Cáceres M. 2011 . Consideraciones sobre la producción de frutas en Venezuela. Rev Bras Fruticultura. 3 (1): 18798.

Castro D, Días J, Montoya N. 2002. Propagación clonal de bananos en birreactores de inmersión temporal. In: Acorbat. Memorias XV reunión realizada en Cartagena de Indias, Colombia, 27 de octubre al 2 de noviembre de 2002. Medellín, Colombia. Asociación Colombiana de Bananeros (AUGURA); $\mathrm{p}$ 44-8.

Colmenares M, Giménez C. 2003. Multiplicación in vitro Musa ssp. mediante el sistema de inmersión temporal. p. 46877. Consultado septiembre de 2014. URL disponible en: www.revfacagronluz.org-ve

Grisales F. 1994. Técnica rápida de multiplicación de plátano en Colombia. INFOMUSA. 3 (2): 7.

Hoyos JL, Román PC, Velasco JR. 2008. Evaluación del efecto de diferentes concentraciones de fitohormonas en la propagación de plátano dominico hartón (Musa AAB Simmonds). Facul Cien Agropec. 6 (2): 99-104.

Hoyos J, Perea R, Velasco R. 2008. Evolución del efecto de diferentes concentraciones de fitohormonas en la micropropagación de plátano dominico hartón (Musa AAB Simmonds). Biotecnología en el sector agropecuario y agroindustrial. 6 (2): 7-18.

Murashige T, Skoog F. 1962. A revised medium for rapid growth and bioassays with tabacco tissue cultures. Physiol Plant. 15: 473-97.

Ortega DF, Tamayo AC, Calderón J, Galván R. 2011. Establecimiento aséptico en la micropropagación in vitro de banano Williams AAA subgrupo Cavendish. Tierra Tropical. 7 (2): 205-20.

Pérez OP, García L, Bermúdes I, Veitia V, Romero C. 2002. Manejo hijuelos y ápices de cultivar de Musa spp. para iniciar la micropropagación y comportamiento durante seis cultivares in vitro. Biotecnol Veg. 2 (2): 77-81.

Pérez Z, García LB, Sarria Y, Clavero J. 2002. Alternativa para la propagación in vitro del cultivar hibrido FHIA-20. InfoMusa 8 (20): 35-8.

Pérez MB, Medero VV, Torres MD, López JT, Santos AP, Rayas $\mathrm{AC}$, et al. 2011. Nueva alternativa para la micropropagación en inmersión temporal del cultivar del plátano vianda INIVITPV-2011(AAB). Rev Colomb Biotecnol. XV (1): 98-107.

Ramírez M, Lindorf H, García E. 2008. Cambios morfoanatómicos en los ápices y del vástago y de la raíz del banano Williams (Musa sp. AAA) bajo distintas concentraciones de N6- bencil Adenina. J Agricult Univ Puerto Rico. 92 (1-2): 53-72.

Ríos G, Añez M, Ramírez M, Bracho M, Araújo D, Suárez H, et al. 2013. Cultivo in vitro de yemas tratadas con benciladenina proveniente de cormos enteros o seccionados de plátano «Cambur Manzano». Bioagro. 25 (2): 137-42.

Sandoval J, Brenes G, Pérez L. 1991. Micropropagación de plátano y banano (Musa $A A A, A A B$ ) en el CATIE. Serie técnica, informe técnico. Turrialaba: CATIE $N^{\circ} 186 ; 29$ p.

Sandoval J, Müller L. 1985. Influencia del tamaño del explante en la propagación in vitro de cuatro cultivaciones de Musa. VII Reunión de la ACORBAT. San José, Costa Rica; vol. 21.p. 87-97.

Sepúlveda N, Murillo M, Medina M. 2008. Propagación in vitro de musáceas del Chocó a partir de meristemos radiculares. Revista Universidad Tecnológica del Chocó: Investigación, Biodiversidad y Desarrollo 27 (1): 96-9. 
Silva A, Trujillo I, Vidal M, Pérez V. 2009. Evaluación de la inducción de variabilidad genética en cambur manzano (Musa AAB) a través de marcadores RAPD. Agron Trop. 59 (4): 413-22.

Silva A, Trujillo G, Salazar E. 2010. Proliferación in vitro de brotes de plantan hartón (Musa AAB, subgrupo plátano CV hartón). Biotecnol Veg. 4 (6): 220-30.

Simmonds NW. 1962. The evolutions of bananas. London: Longmans; $170 \mathrm{p}$.

Simmunds NW. 1973. Los plátanos. Barcelona: Blume; 39 p.
Simmunds NW, Sherphered K. 1955. Taxomony and origen of the cultivated banana. J Linn Soc Lond Bot. 55: 302-12.

Soto M. 1992. Bananos. Cultivos y comercialización. $2^{\text {a }}$ ed. San José: Litografía e imprenta LIL. 640 p.

Tezenas DMH. 1985. Le bananier plantain. Malsone. Paris: Uve y Larouse; 143 p.

Vuylsteke D, De Lange E. 1988. Shoot-tip propagation, conservation y distribution of Musa germplasm. Rome: IBPGR; 55 p. 